\title{
El abandono infantil en Tenerife a finales del Antiguo Régimen
}

\author{
Foundlings in Tenerife at the End of the Ancient Regime
}

\author{
Paula Barbero \\ Universidade de Santiago de Compostela \\ https://orcid.org/0000-0001-6674-1985 \\ pau_barbero@hotmail.com
}

Recibido: 30/03/2020; Revisado: 07/07/2020; Aceptado: 22/10/2020

\begin{abstract}
Resumen
Gracias a la documentación referida a la Casa Cuna de La Laguna, se ha estudiado la práctica social del abandono infantil en Tenerife a finales del siglo xVIII. Su análisis ha servido para reconstruir la frecuencia, las horas y la estacionalidad en la cual se producían las entradas registradas en la inclusa, como también la geografía de la exposición infantil o el sistema de recepción que la institución ofrecía a las criaturas abandonadas. Luego, en un segundo momento, hemos atendido a los cambios y permanencias que experimentó el fenómeno en el curso del siglo XIX.
\end{abstract}

Palabras claves: Abandono infantil, Casa Cuna de La Laguna, Tenerife, siglos XVIII-XIX.

\begin{abstract}
Based on documentation stemming from the Foundling Hospital of La Laguna, this article analyses the social practice of child abandonment in Tenerife at the end of the eighteenth century. This analysis recounts the frequency, hours and seasonality of the entries registered at the foundling hospital, as well as the geography of each abandoned child and the intake system offered to foundling infants by the institution. Subsequent to this, we have analysed the consistencies versus the changes that the phenomenon underwent during the nineteenth century.
\end{abstract}

Key words: Foundlingst, Foundling Hospital of La Laguna, Tenerife, Eighteenth-Nineteenth Centuries. 


\section{INTRODUCCIÓN ${ }^{1}$}

El profesor Antonio Eiras Roel dio a conocer en 1967 la primera investigación realizada en España sobre los niños expósitos en la Edad Moderna (EIRAS, 1967). Se trataba de un estudio que ponía la atención en el análisis de los recién nacidos abandonados y acogidos en el Hospital Real de Santiago de Compostela durante el siglo XVIII. Su estudio fue ampliado en 1976 para el siglo XIX por José Manuel PéreZ GARCía (1976). Por otro lado, Teófanes Egido publicó en 1973 su primer trabajo dedicado a los niños expósitos en Valladolid entre los siglos XVI-XVIII (EGIDO, 1973), y luego, expuso parte de esos mismos resultados en las I Jornadas de Metodología Aplicada a las Ciencias Históricas, celebradas en 1975 en la Universidad de Santiago (EGIDO, 1975). Desde entonces, los historiadores comenzaron a interesarse por la investigación de las casas cunas españolas (Demerson, 1972; SANTAló, 1977). ${ }^{2}$ A raíz de ello, en los años ochenta proliferaron numerosos análisis del fenómeno a nivel regional (Soubeyroux, 1980; Galicia Pinto, 1985; Dubert, 1988; Lamsfus, 1991; Fuente, 2000; Pérez Álvarez, 2008; Sobrado, 2018). Por esos años, la historiografía canaria realiza también sus propias contribuciones al conocimiento de la exposición infantil que tenía lugar en las inclusas del Archipiélago (MARTín Ruíz y Díaz Rodríguez, 1982; Lobo y Sediles, 1988; Santana Pérez, 1993; Lobo, López y Torres, 1993; Quintana y Lobo, 1996; Torres y Lobo, 1996; Rodríguez Yanes, 1997; HeRnÁNdez GonZÁlez, 1998; LobO y RodRíGueZ, 2002; LeÓN, 2015; LoBO, 2009; Santana Pérez, 2017; Pérez Morera, 2019).

Gracias a estas y otras aportaciones, disponemos en la actualidad de una bibliografía inabarcable acerca de los niños expósitos que fueron entregados en las inclusas españolas durante el Antiguo Régimen. Investigaciones que estudian el tema desde diferentes perspectivas: legislativa, es decir, a través de las leyes promulgadas y de los escritos de denuncia llevados a cabo por los gobiernos, la Iglesia y los sectores ilustrados; institucional, sobre el funcionamiento interno de las inclusas locales y su articulación sobre el territorio; demográfica, basados en los análisis cuantitativos sobre los ritmos, fases y estacionalidad de las entradas y de la mortalidad registradas en las casas cunas; social, centrados principalmente en las mentalidades; documental, merced a las aportaciones que dan a conocer nuevas fuentes escritas y sus posibilidades de análisis; e incluso desde un punto de vista artístico y arquitectónico, a partir de los edificios de los hospitales que en la época albergaron a las inclusas.

Nuestra investigación aborda el abandono infantil en la isla de Tenerife a finales del Antiguo Régimen. Con este objetivo, hemos hecho uso de la documentación disponible para reconstruir la exposición de recién nacidos en la Casa Cuna de La Laguna. Con ella, pretendemos, primero, rastrear sus confusos orígenes y su gestión administrativa, para lo que hemos tenido en cuenta la información que por

1 Quiero agradecer las consideraciones de los/as evaluadores anónimos, las cuales han contribuido a mejorar el presente trabajo. Con especial estima, quiero agradecer al profesor Isidro Dubert por sus inestimables aportaciones y consejos brindados durante el curso de esta investigación.

2 Para una visión en conjunto de las investigaciones realizadas sobre la exposición infantil en España, véase Marcos Martín (1996: 59-86); ToRres y Lobo (1996: 107-112); EgIDO (2003: 393-404); Dubert (2013: 165-210). 
ejemplo aportan las reales cédulas de 1766-1767. Igualmente, hemos acudido a la Memoria descriptiva de los Establecimientos Provinciales de Beneficencia en la Provincia de Canarias de 1887, ${ }^{4}$ ya que nos ofrece una visión global de las fundaciones y de la situación en que se hallaban los hospitales que había en Tenerife. En un segundo momento, nos hemos servido de los datos del censo de Floridablanca (1787), para poner en relación en cada espacio geográfico donde eran encontradas las criaturas abandonadas con la importancia de su población. Hemos consultado asimismo los registros confeccionados por los administradores de la Casa Cuna de La Laguna, la mayoría de las veces libros de asientos, explotando el contenido de las partidas individuales de los niños expósitos recibidos en el establecimiento. ${ }^{5}$ El análisis de estos registros nos permite seguir la trayectoria vital de las criaturas desde el mismo momento que eran recogidas en la casa hasta que eran reconducidas a los hogares de las amas de leche o, y en la mayoría de los casos, en que murieron bajo la tutela de la institución. En este sentido, el manejo de la información contenida en el Libro de asiento de la Casa Cuna de La Laguna en 1752-17946 nos permitirá hacernos una idea acerca de la evolución de la exposición en la corta duración. Para una visión más a largo plazo usaremos los resultados de las investigaciones de Juan Manuel Santana Pérez (1993: 94-101), sobre los ingresos en la Casa Cuna de La Laguna entre 1811 y 1833, cuyo contenido hemos puesto en relación con los análisis que hemos realizado a partir de los datos extraídos del Libro de asiento de 1844-1846 de la Casa Cuna de La Laguna. ${ }^{7}$ Información ésta, que se completó con documentación procedente de la Casa de la Maternidad y Expósitos de Santa Cruz de Tenerife entre 1875 y $1889 .{ }^{8}$

Los datos de estos libros fueron analizados desde un punto de vista cuantitativo. Ahora bien, como en comparación a los demás el libro de asiento de 1752-1794 posee una información de muy buena calidad, por lo que procedimos, además, a construir una base de datos nominativa merced al vaciado de uno de

3 El 20 de noviembre de 1765, don Andrés González Cabrera, capellán del Hospital de los Dolores y administrador de la Cuna de Expósitos, envió al concejo real una petición de ayuda, en la cual solicitaba que el Cabildo de La Laguna o los pueblos de Tenerife, se hicieran cargo anualmente del déficit de 1.400 pesos que la cuna necesitaba para cubrir el pago a las amas de cría y la manutención de los expósitos a su cargo. La mencionada petición fue atendida mediante tres reales cédulas (1766-1767). La real cédula de 20 de febrero de 1766 de Carlos III, por la que se ordena al Comandante General de Tenerife realizar un informe sobre la situación interna de la casa cuna; destino de los niños expósitos; y el caudal de los propios de la ciudad de La Laguna y demás pueblos de Tenerife. La real cédula de 22 de junio de 1767 de Carlos III, por la que establece a la ciudad de La Laguna y a su junta de propios, contribuir anualmente al administrador de la casa cuna con 1.000 pesos corrientes para la lactancia y crianza de los expósitos. Y, la real cédula de 7 de agosto de 1767 de Carlos III, por la cual manda al Comandante General de Tenerife, informar sobre las posibilidades que existían en Tenerife para fundar un centro, donde los niños expósitos fueran educados y criados, después de haber finalizado su período de lactancia con sus respectivas amas de cría y hasta que estuvieran preparados para acceder al mercado laboral. Archivo Histórico Provincial de Santa Cruz de Tenerife (AHPT). Beneficencia, sig. 260.

4 AHPT. Beneficencia, sig. 934.

5 Sobre la tipología documental de los libros de registros de niños expósitos puede consultar SANTALÓ (1977: 493-495).

6 AHPT. Beneficencia, sig. VI-129.

7 AHPT. Beneficencia, sig. VI-133.

8 AHPT. Beneficencia, sig. IV-287. 
cada cuatro años, lo que ha supuesto el manejo del 26,8\% del total de sus partidas. Por esta vía, sabremos lo sucedido a la exposición infantil en once años $(1752,1756$, 1760, 1764, 1768, 1772, 1776, 1780, 1784, 1788 y 1792). Los resultados obtenidos a partir de los mismos nos ayudarán, entre otras cosas, a reconstruir la geografía del abandono infantil; el horario de exposición en el torno; la forma de acceso a la casa cuna; la asistencia que el centro otorgaba a los pequeños; y los ritmos, fases y estacionalidad de los ingresos en la corta (1752-1794), media (1811-1846) y larga duración (1875-1889). Cuestiones estas, que nos permitirán, en última instancia, desentrañar las posibles causas que movían al abandono infantil en la isla de Tenerife al final del Antiguo Régimen. Un empeño que nos ha obligado a poner en relación los resultados obtenidos con las continuidades y rupturas que a este nivel se registraron en el mundo de la exposición infantil en el panorama español y europeo, a la vez que a tener presente las diferentes cuestiones demográficas, económicas y sociales que en el ámbito insular las explican.

\section{EL SISTEMA BENÉFICO-ASISTENCIAL CANARIO Y LA CASA CUNA DE LA LAGUNA DURANTE EL ANTIGUO RÉGIMEN}

Gracias a los estudios realizados en la década de los noventa por SANTANA PÉrEz y LOBO, entre otros, sabemos que el sistema benéfico-asistencial canario destinado a la infancia abandonada, surgió en el siglo XVI y se completó a lo largo de los siglos XVII y XVIII. Las primeras inclusas se instalaron en las ciudades del Archipiélago y su funcionamiento se prolongó hasta bien entrado el siglo XIX y principios del XX. Dicho sistema se articulaba en torno a dos casas cunas principales ubicadas, una, en la isla de Gran Canaria, desde 1647, y otra, en la de Tenerife, desde principios del siglo xVII (Lobo, López y TORRES, 1993: 30; SANTANA PÉreZ, 1993: 49-132; Rodríguez YANES, 1997: 820-823).

Con anterioridad a estas inclusas funcionó un primer centro de acogida en la isla de La Palma desde mediados del siglo XVI (SANTANA PÉREZ, 2017: 145; QuiNTANA y Lово, 1996: 811). La fundación de este centro coincide en el tiempo con la de otras inclusas europeas, como el Hospital Real de Santiago de Compostela, la Inclusa de Madrid o las Casas Cunas de Sevilla, Valladolid, Salamanca, Oporto o Nápoles, las cuales, por su parte, son instituciones posteriores a las abiertas a mediados del siglo XV en Florencia o Guadalupe (EIRAS, 1967: 297-301; FUENTE, 2000: 61-79; FERnÁNDEZ UGARTE, 1988: 42-43; SANTAló, 1980: 19; BARdet, 1991: 6-7; Levene, 2006: 62; Dos Guimarães SÁ, 1992: 124). Esto significa que el grueso de las inclusas canarias, al igual que las peninsulares mencionadas, pertenecerían a la segunda oleada de fundaciones de este tipo que se llevaron a cabo en el ámbito europeo.

Este afán por abrir casas de expósitos en Canarias y en la península sabemos que no culminó entre finales del XVI y mediados del XVII. Hubo una tercera oleada de fundaciones a finales del siglo XVIII, durante la cual surgieron dos nuevas inclusas en el Archipiélago, situadas, respectivamente, en las islas de Lanzarote 
y Fuerteventura (SANTANA PÉREZ, 1993: 122-132). Su aparición coincide con el empeño que la monarquía borbónica puso en esas fechas por regularizar y ordenar la exposición infantil, ya que pensaba, sin al parecer suficiente fundamento, que era un problema generalizado y extendido en el conjunto de la sociedad española de la época (DUBERT, 2013: 160). En esta tercera oleada es cuando aparecen además las inclusas de A Coruña, Mondoñedo, Oviedo, Zamora, Santander, Pamplona, Badajoz, Murcia, Palma de Mallorca, Londres, París o Ruan (REY y SERRANA, 2009: 62; Fuente, 2000: 61-79; Torrubia, 2004: 164; Levene, 2006: 62; BARdet, 1991: 5-7; LAMSFUS, 1991: 1187). A otro nivel y siempre bajo las ideas de la ilustración, el modelo de los grandes "hospitales para niños abandonados", fue exportado desde Europa a mediados del siglo xVIII a los territorios de América y Rusia (GONZALBO, 1982: 409-414; BARDET, 1991: 10-11; GutiÉRREZ y GARCíA, 2010: 79).

En este contexto que estamos describiendo, se sitúa el nacimiento a comienzos del siglo XVII de la Casa Cuna de La Laguna, ${ }^{9}$ ubicada físicamente en el Hospital de Nuestra Señora de los Dolores, fundado en $1507^{10}$ (GONZÁlEZ YANES, 1955: 3251; Cioranescu, 1965: 167; SAnTANa y Monzón, 1995: 109-116; Moyano, 2000: 2372). Pero no será hasta mediados del siglo XVIII cuando en la documentación se observe un funcionamiento sistemático de la casa cuna. Momento, que además, el torno que existía en Santa Cruz se traslada y une al de La Laguna en 1753, quedando el hospital de la capital encargado de recibir y otorgar cuidados a los niños expósitos abandonados en Tenerife durante la segunda mitad del siglo XVIII. ${ }^{11}$ La Casa de Expósitos de La Laguna fue una institución de carácter benéfico-asistencial bajo el control del poder eclesiástico, que se encargó de organizar la recepción y el transporte de los pequeños a la institución desde los lugares donde las criaturas habían sido encontradas. ${ }^{12}$ También se ocupó de articular un sistema de crianza para los niños que conseguían sobrevivir, el cual reposaba sobre las familias que los acogían y que vivían en los alrededores de la ciudad. La finalidad última de la institución era salvar las almas de estos recién nacidos, tratar de evitar el infanticidio y el aborto, y salvaguardar la honra de sus progenitores. Unos objetivos que, sin embargo, no ocultan el deseo de la Iglesia de ejercer por esta vía un cierto grado de control sobre los comportamientos sociales de la población; un deseo que, no evitará la elevadísima mortalidad infantil que se produjo entre los expósitos que la institución llegó a albergar en su seno.

Desde un punto de vista económico, la inclusa de La Laguna se sustentaba sobre las aportaciones de la Iglesia, los pagos irregulares que de vez en cuando

9 La primera donación otorgada a la Casa Cuna de La Laguna fue registrada el 20 de marzo de 1627, al objeto de recoger y dar de lactar a los recién nacidos abandonados por sus padres en la ciudad. AHPT. Beneficencia, sig. 934. Memoria de 1887. AHPT. Beneficencia, sig. 260. Reales cédulas de 1766-1767. Con anterioridad a este hecho, en 1615 se ha evidenciado el pago a un ama de cría por la crianza de un expósito, registrado en un fragmento de cuenta del Hospital de los Dolores (RodRíGUEZ YANES, 1997: 281).

10 AHPT. Beneficencia, sig. 934. Memoria de 1887.

11 AHPT. Beneficencia, sig. VI-129. Libro de asiento, 1752-1794, ff. 20, 32, 46, 75.

12 El administrador, don Santiago Francisco Eduardo, en 1785 describe la inclusa como «una casa baja reducida a dos piezas estrechas, que amenazaba ruina porque algunas paredes se hallan desplomadas» (HeRnÁndeZ GoNZÁLEZ, 1998: 63). 
realizaba el Cabildo insular, contribuciones puntuales que en algún momento pudieran otorgar las autoridades reales y donaciones de los particulares. ${ }^{13}$ En cuanto a su funcionamiento interno, el obispo de Canarias nombraba al capellán del Hospital de Nuestra Señora de los Dolores, quien luego solía ser el administrador principal de la casa. Éste, era responsable máximo del hospital y de la inclusa, donde coordinaba el personal interno y externo, a la vez que atendía los asuntos económicos y administrativos. Solía ser siempre un presbítero, quien percibía a modo de salario un $10 \%$ de cada ingreso económico que llegaba a la cuna. A su lado, había además un administrador interino, que se encargaba de los pagos a las amas de cría y del cuidado general de la Casa de Expósitos, percibiendo por todo ello unos 80 pesos al año (SAnTAna Pérez, 1993: 52-84). Por debajo de esta figura, se situaba la tornera, encargada de recoger y atender de manera inmediata a las criaturas expuestas en el torno, cobrando por ello 10 reales de plata al mes. Asimismo, recibía entre 9 y 12 pesos al año para la adquisición de azúcar, pan, miel, huevos, leche y medicinas destinadas a los niños. ${ }^{14}$ En la base de este organigrama se encontraban los trabajadores externos, o sea, las numerosas amas de crías y el sepulturero de la Iglesia de Nuestra Señora de los Remedios, que recibía cuatro cuartos de real por cada niño enterrado. ${ }^{15}$

Respecto a las amas de cría internas cabe señalar que se observa aquí el empleo de fórmulas diferentes a las imperantes en otras instituciones, ya que éstas no existían en el siglo XVIII y tendremos que esperar hasta la primera mitad del siglo XIX para encontrar su referencia en la documentación. ${ }^{16}$ Por el contrario, en las Casas Cunas de La Palma y Las Palmas trabajaban, respectivamente, dos amas internas; en la isla de La Palma, cada una percibía como salario 570 reales y 6 fanegas de trigo anuales; y en la de Gran Canaria 10 reales de plata y dos cuartillos de aceite mensualmente (SANTANA Pérez, 1993: 103-117). Además, en este último caso, a principios del siglo XIX ya contaba con tres amas (SANTANA PéREZ, 2017: 148). En cambio, el Hospital Real de Santiago disponía de un ama mayor y de dos nodrizas, y a lo largo del siglo XVIII se amplía el número de trabajadoras internas, encargadas de alimentar a los pequeños hasta que eran conducidos a los hogares ubicados en las aldeas gallegas (EIRAS, 1967: 312-320; MARCOS, 1996: 73-79; LAMSFUS, 1990: 237-239; SARASÚA, 1994: 141-144; DUBERT, 2017: 141-142).

La Casa Cuna de La Laguna estaba radicada en la capital, si bien, su influencia se extendía a todo el territorio de Tenerife. En sentido estricto, su funcionamiento no tuvo un claro impacto demográfico sobre la vida de la ciudad, ya que la mayoría de los expósitos eran foráneos y morían a poco de ser recibidos en el torno, mientras que los sobrevivientes eran remitidos a las zonas rurales circundantes para su crianza. No obstante, y al igual a como ocurría en Santiago de Compostela, el mencionado funcionamiento sí tuvo claras repercusiones a nivel social, debido,

13 AHPT. Beneficencia, sig. 260. Reales cédulas de 1766-1767. AHPT. Beneficencia, sig. 934. Memoria de 1887.

14 AHPT. Beneficencia, sig. VI-129. Libro de asiento, 1752-1794, ff.74-75.

15 El sepulturero entre 1752 y 1756 recibió 211 reales por los niños expósitos enterrados en La Laguna. AHPT. Beneficencia, sig. VI-129. Libro de asiento, 1752-1794, ff.74-75.

16 AHPT. Beneficencia, sig. 934. Memoria de 1887. 
en buena medida, al elevado número de personas que se desplazaban hasta La Laguna para abandonar a sus pequeños, sea porque hubieran nacido fuera del matrimonio, sea porque la coyuntura económica impedía a las familias su manutención, o sea por cualquier otra razón. A este trasiego de padres, madres y familiares, se sumaba a su vez el de los conductores encargados de transportar a los niños abandonados desde lugares distantes a la capital, muchas veces las parteras o comadres que habían asistido a las mujeres en los nacimientos, y el de las amas externas, que iban a recoger a los niños supervivientes para criarlos en los alrededores a cambio de un salario ${ }^{17}$ (SOBRADO y DUBERT, 2012: 136-138).

La Casa Cuna de La Laguna permaneció en funcionamiento hasta mediados del siglo XIX. Su desaparición, más bien, su «mutación» institucional, se enmarca en el cierre generalizado que conocieron las tradicionales inclusas europeas a partir de las décadas de 1850 y 1860, en un intento de las autoridades por poner «Coto» tanto al abandono infantil como a la elevada mortalidad que se derivaba del mismo (LEVENE, 2006: 62; CoRsinI, 1996: 306). En este contexto, se sitúa su traslado y la actividad sistemática desarrollada ahora en la inclusa de Santa Cruz, de ésta dependían dos hijuelas establecidas, una, en el Hospital de la Concepción del puerto de Garachico y otra, en el Hospital de Dolores de Santa Cruz de La Palma. ${ }^{18}$ Además, el Hospital de la Trinidad de La Orotava y el Hospital de San Sebastián de La Laguna, funcionaban como casas de recepción y traslado de expósitos hacia Santa Cruz. Dependían, también de ella todos los expósitos que los alcaldes de La Gomera y El Hierro recogían y alimentaban hasta que las criaturas fueran capaces de soportar el viaje a Tenerife, donde finalmente accederían a la Casa de Huérfanos y Desamparados de Santa Cruz. ${ }^{19}$

\section{SISTEMA DE RECEPCIÓN Y ASISTENCIA EN LA CASA CUNA DE LA LAGUNA, 1752-1794}

Entre las causas que propiciaban el ingreso de un recién nacido en la inclusa estaba además el fallecimiento de uno de los cónyuges. Por tanto, los viudos y

17 «María Dominga de la Concepción, expósita del puerto de Santa Cruz, la ha entrado en la cuna esta tarde [12 de mayo de 1776] a horas de las 5, Catalina de Llerena, vecina de dicho puerto, y de profesión comadre, quien expresó haber nacido anoche entre las 11 y 12, que no se había bautizado, y que su madre era pobre. Le bautizó hoy en la parroquia de Nuestra Señora de la Concepción de esta ciudad. Murió en 17 de junio de 1776». AHPT. Beneficencia, sig. VI-129. Libro de asiento, 1752-1794, f. 243.

18 La Casa Inclusa de Santa Cruz, denominada Casa de la Maternidad y Expósitos, dependía de la Provincia de Canarias, quien ahora sustituía al Obispado en su gestión y se hacía cargo de sus gastos. Se hallaba ubicada en la calle de La Caleta en una casa arrendada a propiedad particular. En su interior no guardaba las condiciones higiénicas necesarias, pues carecía de dormitorios separados para los expósitos y las nodrizas que los lactaban. AHPT. Beneficencia, sig. 934. Memoria de 1887.

19 Esta casa fue fundada en 1849 con la finalidad de recoger a los niños huérfanos hasta los 15 años, que vagaban y mendigaban por las calles de la ciudad. Estaba ubicada en la calle de La Noria, y en su interior se dividía en dos secciones: una casa de propiedad de la beneficencia destinada a los niños; y otra, de propiedad privada para las niñas. Allí unos pocos aprendían a leer, escribir y a veces hasta algún oficio. La mayor parte de ellos fueron prohijados a tempranas edades por familias que vivían en diferentes zonas de Tenerife. AHPT. Beneficencia, sig. 934. Memoria de 1887. 
viudas debían sostener a sus pequeños, pero sí no tenían medios económicos, podían dejarlos en la casa cuna de forma temporal o definitiva. ${ }^{20}$ Una situación similar se daba en aquellos matrimonios donde uno de sus integrantes se encontraba cumpliendo condena en la prisión, ${ }^{21}$ entre las solteras que vivían en las calles y se mantenían con limosnas, ${ }^{22}$ o entre las casadas cuyos maridos se hallaban embarcados o ausentes por causa de la emigración hacia América. ${ }^{23}$ Pese a todo, unas situaciones personales y sociales detrás de las cuales casi siempre estaban las dificultades materiales, la marginación y la pobreza.

Para evitar estos males a los pequeños y solventar este tipo de situaciones personales y familiares, siempre con la esperanza de que fuesen acogidos temporalmente, la administración de la casa cuna creó un sistema centralizado de traslado de los niños expósitos a La Laguna. Éste, tomaba como base las diferentes feligresías isleñas, desde donde sus párrocos trataban de averiguar la filiación de las criaturas que aparecían abandonadas y de remitirlas luego a la inclusa. La finalidad de esta especie de red era canalizar la exposición infantil hacia un único punto. Al respecto, contamos con informaciones que nos indican que en la ciudad de La Laguna y en el puerto de Santa Cruz, la casa tenía de mano un pequeño grupo de mujeres -que solían ser las parteras o las comadres-, quienes actuaban como intermediarias entre las madres y el personal de la inclusa. Después de haber asistido a su parto y llevar a la criatura consigo, se encargaban de dejar al pequeño en la casa cuna, ya fuese en los brazos de la tornera o en los del administrador. ${ }^{24}$ Una fórmula muy parecida a la que a mediados del siglo XVIII funcionaba también en Italia y en el resto de la Europa meridional (LEVENE, 2006: 65; LAMSFUS, 1991: 1189).

La Casa Cuna de La Laguna recibía a los nacidos fuera del matrimonio y a aquellas criaturas cuyos padres no disponían de medios materiales para

20 «María Josefa de la Concepción, expósita de La Laguna, hija de legítimo matrimonio de Marejal González y Manuela Ramos, y por haber muerto ésta del parto, y quedándole ocho hijos, con mucha pobreza, se admitió en la cuna el 2 de octubre de 1766». AHPT. Beneficencia, sig. VI-129. Libro de asiento, 1752-1794, f.165.

21 «Francisco Javier de la Concepción, expósito de Icod de los Vinos, hijo legítimo de Manuel Francisco Delgado, preso en la cárcel de esta ciudad y de Isabel de la Ascensión, difunta hace tres días, vecinos de dicho lugar. Siendo notoria la pobreza de su padre, se recibió en la cuna el 31 de marzo de 1775, fue entregado a su tía María Martín el 7 de julio». AHPT. Beneficencia, sig. VI-129. Libro de asiento, 1752-1794, f. 218.

22 «José de Santa Catalina, expósito del lugar de Tacoronte, hijo de una pobre pidiente de estado libre. Se recibió en la cuna el 18 de octubre de 1778 y murió el 8 de octubre de 1780». AHPT. Beneficencia, sig. VI-129. Libro de asiento, 1752-1794, f. 297.

23 «Antonio Francisco María de la Concepción, expósito de esta ciudad, que condujo a la cuna este día [1 de febrero de 1780] María Lorenzo, mujer de José Silvera, vecina del Pago de Geneto, expresando ser hijo de una mujer casada, pobre y con su marido ausente, presentó papel de haberse bautizado en la parroquia de Nuestra Señora de la Concepción el 29 de enero pasado de este año. Murió en 6 de octubre de 1780». AHPT. Beneficencia, sig. VI-129. Libro de asiento, 1752-1794, f. 329.

24 «Fructuoso Juan Evangelista de los Remedios, expósito de la ciudad de La Laguna, que condujo el día 29 de diciembre de 1776 a la cuna la comadre María Santos. Fue bautizado hoy en la parroquia de Nuestra Señora de la Concepción, según certificación autorizada que presentó la susodicha, con papel para que se le pusiera ese nombre. Traía unos escapularios de Nuestra Señora del Carmen de bordado de seda. Murió en 21 de julio de 1777». AHPT. Beneficencia, sig. VI-129. Libro de asiento, 1752-1794, f. 257 . 
mantenerlos. En estas condiciones, la situación de carestía vivida en Tenerife durante el siglo XVIII a causa de la prolongada crisis que provocó la caída del sector vitivinícola en Canarias (MAcíAs, 1995: 168-181), explicaría que las autoridades religiosas de la isla procediesen a organizar el funcionamiento de esa red de recepción de criaturas abandonadas.

Una vez que el expósito entraba en la casa cuna, el administrador comprobaba si estaba bautizado, y ante la ausencia del correspondiente certificado procedía a bautizarlo de inmediato. Había dos modalidades de cristianar a los pequeños y la elección de una u otra dependía de su estado de salud. Sí estaban sanos, el bautismo era efectuado por el capellán en la Iglesia de Nuestra Señora de los Remedios, situada a unos 200 metros del hospital; por el contrario, si estaban enfermos, entonces, las criaturas recibía el agua de socorro nada más llegar a la institución. Así sucedió, por ejemplo, con las gemelas María de la Concepción y Antonia de la Concepción, depositadas en el torno la noche del 24 de mayo de 1782, tras comprobar su mal estado de salud, el capellán se apresuró a otorgarles el agua de socorro y, unos instantes después, murieron. ${ }^{25}$

Hay constancia de la fecha de bautismo en un $49 \%$ de las partidas manejadas. Por ellas sabemos que un 38,2\% de los expósitos eran cristianados el mismo día de su ingreso en la inclusa y un 17,8\% al día siguiente, por haberse producido ese ingreso durante la noche, esto es, con anterioridad a medianoche, igual a como sucedía por ejemplo en la inclusa de A Coruña (LóPEz Picher, 2006: 611). Sabemos que un $29 \%$ de las criaturas fueron bautizadas el día previo a su entrada en la casa, mientras que un 15\% lo eran entre dos y nueve días antes de la misma (Tabla 1). En este último caso, tan temprana recepción del sacramento se explica por el tiempo que tardaban los pequeños en llegar al hospital desde puntos de remisión muy alejados de La Laguna. ${ }^{26}$

TABLA 1

Momento del bautismo de los expósitos, 1752-1794

\begin{tabular}{|l|c|c|}
\hline $\begin{array}{l}\text { Tiempo que media entre el bautismo y el ingreso } \\
\text { de los niños en la inclusa }\end{array}$ & Núm. casos & Porcentajes \\
\hline El mismo día del ingreso & 275 & 38,2 \\
\hline Al día siguiente del ingreso & 128 & 17,8 \\
\hline Un día antes del ingreso & 209 & 29 \\
\hline Dos días antes & 56 & 7,8 \\
\hline Tres días antes & 21 & 2,9 \\
\hline
\end{tabular}

25 AHPT. Beneficencia, sig. VI-129. Libro de asiento, 1752-1794, ff.374-375.

26 «Fernando Gerónimo Tomás del Rosario, expósito del lugar de Santa Úrsula, abandonado en la casa de Úrsula Ravelo, quien lo expuso el día 7 de enero de 1776 por la noche en aquella parroquia, se remitió por el cura de dicho lugar, con papel de estar bautizado en dicha parroquia el 8 del mismo, y de haberse detenido hasta el día 13 a causa de las lluvias. Murió en 12 de enero de 1777». AHPT. Beneficencia, sig. VI-129. Libro de asiento, 1752-1762, f. 254. 
El abandono infantil en Tenerife a finales del Antiguo Régimen

\begin{tabular}{|l|c|c|}
\hline Entre 4 a 9 días antes & 23 & 3,2 \\
\hline Más de 10 días antes & 8 & 1,1 \\
\hline TOTAL & $\mathbf{7 2 0}$ & $\mathbf{1 0 0}$ \\
\hline
\end{tabular}

Fuente: AHPT. Beneficencia, sig. VI-129. Libro de asiento, 1752-1794. Elaboración propia.

La crianza ofrecida por la Casa Cuna de La Laguna a los expósitos que lograban sobrevivir recaía sobre los hogares de las nodrizas externas, quienes recibían por su trabajo 10 reales de plata al mes por criarlos junto a sus hijos. ${ }^{27}$ Por su parte, las nodrizas de Las Palmas cobraban poco más de 6 reales de plata al mes (SANTANA Pérez, 1993: 84-103). En La Laguna, los hogares de éstas se ubicaban en las comarcas más próximas a la ciudad, situadas a una distancia inferior a los 15 kilómetros de la misma. Esta cercanía entre el hospital y los hogares reducía el tiempo que los expósitos permanecían en el interior de la institución hasta que eran acogidos por estas mujeres, quienes no solían tardar más de uno a dos días. Asimismo, reducía también el peligro que para la vida y salud del pequeño podía darse en el curso del desplazamiento, a la vez que permitía a los administradores supervisar su crianza de una manera fácil y rápida. Un esquema similar a éste lo encontramos en Medina del Campo o en Santiago de Compostela, donde se forzaba a que las distancias no superasen los 30 o 40 kilómetros (MARCos, 1978: 139; EIRAS, 1967: 322-324; LAMSFUS, 1990: 239-243; TORRUBia, 2004: 157-168).

En la elección de las nodrizas, la dirección de la casa no solo tenía en cuenta la vecindad sino también su estado civil (Tabla 2), conocido en el 90\% de los casos. Sabemos entonces, que en el $86 \%$ de las ocasiones las amas eran mujeres casadas. En la toma de una criatura a su cargo, el marido actuaba como garante de su esposa, sea en el cumplimiento del servicio que ofrecían a la institución, sea, y en general, en todos y cada uno de los aspectos de su vida. Sin embargo, estar casada no era un requisito imprescindible para acceder a este empleo, ya que un $10 \%$ de las amas fueron viudas y un $4 \%$ solteras. Un comportamiento diferente lo podemos encontrar en la inclusa del Hospital de León, donde por las mismas fechas, la mayoría de las nodrizas eran casadas, exactamente el 96,4\%, las viudas un $2,9 \%$ y las solteras un $0,7 \%$, avecindadas unas y otras en comarcas de montaña relativamente alejadas de la ciudad (Pérez Állvarez, 2008: 124). O en la inclusa de A Coruña, donde hasta 1793 las nodrizas solían ser solteras que residían en la ciudad. Solo con posterioridad a esta fecha, la lactancia de auxilio se dio en los hogares de amas externas, ahora ya casadas, que vivían en las aldeas próximas a la urbe, como sucedía en Tenerife (López Picher, 2006: 612).

27 AHPT. Beneficencia, sig. 260. Reales cédulas de 1766-1767. 
TABLA 2

Estado civil de las amas de cría, 1752-1772

\begin{tabular}{|c|c|c|}
\hline Estado civil & Núm. casos & Porcentajes \\
\hline Solteras & 20 & 3,4 \\
\hline Casadas & 501 & 86,2 \\
\hline Viudas & 60 & 10,3 \\
\hline TOTAL & $\mathbf{5 8 1}$ & $\mathbf{1 0 0}$ \\
\hline
\end{tabular}

Fuente: AHPT. Beneficencia, sig. VI-129. Libro de asiento, 1752-1772. Elaboración propia.

Los expósitos en Tenerife permanecían junto a sus nodrizas hasta que alcanzaban los tres años, momento en que volvían al hospital para pasar a un hogar adoptivo. Esta salida de la inclusa se producía en Gran Canaria a partir del año y medio, y en Florencia y Londres a partir de un año (LOBO, 1993: 80; LEVANE, 2006: 63). Por el contrario, si nadie los prohijaba, entonces se les obligaba a dejar el centro, entrando de este modo en el mundo de la marginalidad existente en las calles de La Laguna (SANTANA Pérez, 1993: 61).

\section{GEOGRAFÍA Y MOMENTO DEL ABANDONO INFANTIL EN TENERIFE, 1752-1794}

Todo el territorio de Tenerife se vio implicado en el envío de niños y niñas a la Casa Cuna de La Laguna (Mapa 1, infra). Ahora bien, entre 1752 y 1794 existieron tres ámbitos geográficos donde la exposición infantil tuvo una mayor incidencia. Primero, el 79,5\% de los abandonos fueron realizados en el espacio urbano o semiurbano: en la capital (el $44 \%$ del total), y en los enclaves más importantes a nivel económico, político o demográfico de la isla, caso del puerto de Santa Cruz (el 23,9\%), y de la villa de La Orotava (el 11,6\%). Segundo, un 15,9\% del total de los expósitos aparecieron en la franja norte de la isla, concretamente en las jurisdicciones de Tacoronte, La Matanza, La Victoria, Puerto de la Cruz, Los Realejos y Garachico, muy relacionados todos ellos con la producción y comercialización del vino y, por tanto, con la crisis agrícola que ahora se vivía en el campo tinerfeño. Tercero, un $4,6 \%$ de las criaturas fueron encontradas en distintas comarcas rurales del norte $(2,5 \%)$ y sur $(1,6 \%)$ de Tenerife, y en los enclaves que rodeaban a la capital $(0,5 \%)$. 


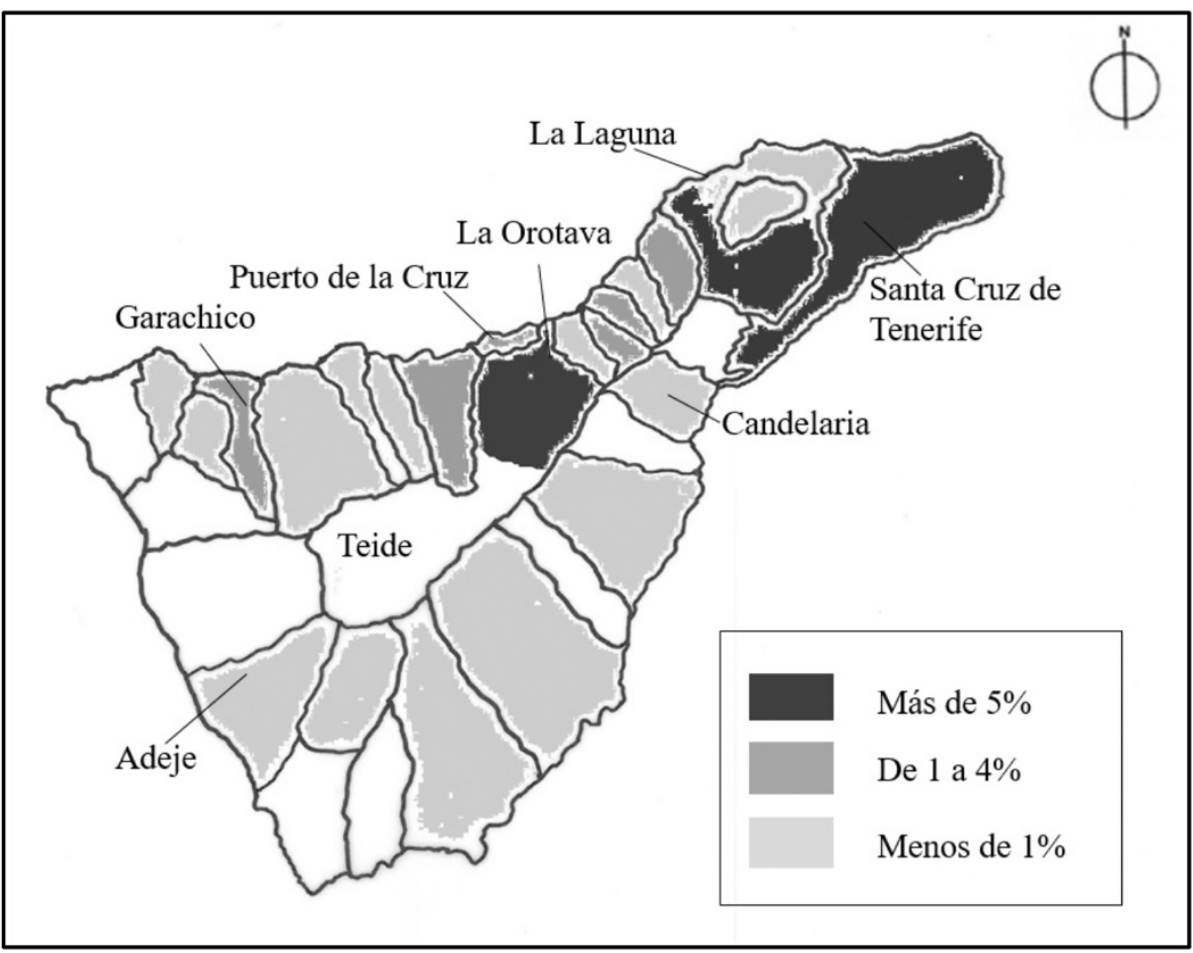

Mapa 1. Geografía del abandono infantil en Tenerife, 1752-1794 (porcentajes con respecto al total de expósitos abandonados en la casa cuna). ${ }^{28}$ Fuente: AHPT. Beneficencia, sig. VI-129. Libro de asiento, 1752-1794. Elaboración propia.

Sabemos entonces que en la isla el abandono infantil se concentraba en desigual grado en cuatro ámbitos poblacionales: la capital y sus inmediaciones (44\% del total), los puertos comerciales y sus alrededores (28\% del total), la villa de La Orotava y los suyos (12\% del total) y el mundo rural sensu strictu (16\% del total). Teniendo en cuenta que en 1787 el 62\% de los habitantes de Tenerife vivía en el campo (véase Tabla 3), estos datos nos indican que la tendencia de quienes exponían era la de dejar a los recién nacidos lo más cerca posible de la ciudad o en aquellos enclaves con una determinada entidad, bien fuese porque allí se encontraba la casa cuna o bien porque desde ellos era más fácil que fuesen encontrados y remitidos de inmediato a la capital.

28 Los límites geográficos señalados en el mapa corresponden a las divisiones municipales actuales, por tanto, su utilidad en el mismo solo responde a una mera cuestión orientativa. 
TABLA 3

Lugares del abandono infantil, 1752-1794 y distribución de la población en 1787

\begin{tabular}{|l|c|c|}
\hline & $\begin{array}{c}\text { Porcentajes de } \\
\text { expósitos }\end{array}$ & $\begin{array}{c}\text { Porcentajes de } \\
\text { población en 1787 }\end{array}$ \\
\hline Capital & 44 & 12 \\
\hline Puertos comerciales & 28 & 17 \\
\hline Villa & 12 & 9 \\
\hline Rural & 16 & 62 \\
\hline Total & 100 & 100 \\
\hline Número de casos & $\mathbf{1 . 4 6 7}$ & $\mathbf{6 3 . 3 2 2}$ \\
\hline
\end{tabular}

Fuentes: Censo de Floridablanca. AHPT. Beneficencia, sig. VI-129. Libro de asiento, 1752-1794. Elaboración propia.

De hecho, el mayor porcentaje de criaturas abandonadas se registró en la mencionada capital y sus inmediaciones (Tabla 3), lo que significa que la primera funcionaba como foco de atracción para todo el territorio isleño. No en vano, y a través de las partidas que hacen referencia al lugar de aparición de los menores (el $54 \%$ del total de las manejadas), sabemos que tres de cada cuatro eran expuestos en el torno de la institución. Visto que en 1787 residían fuera de la jurisdicción de La Laguna 55.847 de los 63.322 habitantes de Tenerife, es decir, el $88 \%$ de la población, parece obvio que el grueso de quienes se decidían abandonar a sus hijos optaban para hacerlo por desplazarse personalmente o por persona interpuesta hasta la ciudad (Tabla 3). Entre las razones apuntadas, por las posibilidades que ofrecía además para preservar el anonimato. Así, por ejemplo, a las solteras que habían mantenido relaciones prematrimoniales, la exposición en La Laguna les ayudaba a mantener intacta su honra en sus lugares de origen y a continuar aspirando, por tanto, a participar en el limitado mercado matrimonial de los mismos. Una situación similar vivirían muchas mujeres casadas con emigrantes, pues podían abandonar a la criatura de manera anónima, quizás, ante las dificultades materiales con las que se encontraban para sostenerla. Además, unas y otras, al exponer a los pequeños en lugares distantes a su domicilio habitual burlaban la vigilancia parroquial y social que pesaba sobre ellas, toda vez que imposibilitaban a los curas anotar en las partidas bautismales a los niños expósitos que habían nacido en su feligresía.

Estas situaciones nos ayudan a entender que el $87 \%$ de los abandonos que se producían en el torno situado en la fachada de la Casa Cuna de La Laguna tuviesen lugar entre las 7 de la tarde y las 6 de la madrugada. Es decir, se iniciasen al atardecer (concentrándose el 58\% de las exposiciones entre las 7 de la tarde y las 12 de la noche), y continuasen durante toda la noche hasta el rayar del alba. Un horario de exposición que variaba según el paso de las estaciones. Así, por ejemplo, tras el verano, durante el otoño e invierno, a medida que se reducía 
la claridad del día a partir de las 7 de la tarde, se incrementaba el número de criaturas abandonadas en el torno, para luego cambiar de signo con la llegada de la primavera (Tabla 4).

En suma, nos hallamos ante un calendario de exposiciones marcadamente nocturno -lo cual indica que el abandono no era una práctica socialmente admitida como normal y habitual en el marco de la sociedad isleña, sino, más bien, todo lo contrario-, que además, estaba sometido a una variación estacional. Dos características estas, muy similares a las encontradas en otras inclusas españolas y europeas de la época (DUBERT, 2013: 155-156).

TABLA 4

Momento en que se realizaba la exposición en el torno, 1776-1783

\begin{tabular}{|c|c|c|c|c|c|}
\hline & VERANO & OTOÑO & INVIERNO & PRIMAVERA & TOTAL \\
\hline Horas del día & $\%$ & $\%$ & $\%$ & $\%$ & $\%$ \\
\hline 1 & 1,1 & & 2,3 & & 0,7 \\
\hline 2 & & 2,0 & 1,1 & 5,3 & 2,4 \\
\hline 3 & 7,8 & 3,9 & 4,6 & 4,6 & 5,1 \\
\hline 4 & 16,7 & 7,8 & 2,3 & 6,9 & 8,3 \\
\hline 5 & 6,7 & 10,8 & 9,2 & 6,1 & 8,0 \\
\hline 6 & 2,2 & 1,0 & 10,3 & 3,8 & 4,1 \\
\hline 7 & 2,2 & & 2,3 & 2,3 & 1,7 \\
\hline 8 & 2,2 & 2,9 & 2,3 & 0,8 & 1,9 \\
\hline 9 & 1,1 & & 1,1 & 1,5 & 1,0 \\
\hline 10 & & 1,0 & 3,4 & 1,5 & 1,5 \\
\hline 11 & & 1,0 & 1,1 & 0,8 & 0,7 \\
\hline 12 & 1,1 & 2,0 & 1,1 & & 1,0 \\
\hline 13 & & & 1,1 & & 0,2 \\
\hline 14 & & 1,0 & 2,3 & & 0,7 \\
\hline 15 & 1,1 & & 0,0 & & 0,2 \\
\hline 16 & 2,2 & & 2,3 & 1,5 & 1,5 \\
\hline 17 & 3,3 & 1,0 & 0,0 & 0,8 & 1,2 \\
\hline 18 & & 4,9 & 3,4 & & 1,9 \\
\hline 19 & 6,7 & 19,6 & 23,0 & 10,7 & 14,6 \\
\hline 20 & 20,0 & 28,4 & 12,6 & 26,0 & 22,3 \\
\hline 21 & 23,3 & 4,9 & 10,3 & 18,3 & 14,3 \\
\hline 22 & 1,1 & 2,0 & 1,1 & 2,3 & 1,7 \\
\hline
\end{tabular}




\begin{tabular}{|c|c|c|c|c|c|}
\hline 23 & & 3,9 & 1,1 & 2,3 & 1,9 \\
\hline 24 & 1,1 & 3,9 & 1,1 & 4,6 & 2,9 \\
\hline Total & 100 & 100 & 100 & 100 & 100 \\
\hline Núm. casos & $\mathbf{9 0}$ & $\mathbf{1 0 2}$ & $\mathbf{8 7}$ & $\mathbf{1 3 1}$ & $\mathbf{4 1 2}$ \\
\hline
\end{tabular}

Fuente: AHPT. Beneficencia, sig. VI-129. Libro de asiento, 1776-1783. Elaboración propia.

Fuera ya de la capital, en el mundo rural, cada vez que alguien se encontraba con una criatura abandonada recurría al cura del lugar, quien asistía al expósito en primera instancia. Asimismo, también podían dirigirse a él los padres o la madre soltera del pequeño cuando les era imposible mantenerlo consigo a causa de su pobreza y precariedad material. Esta primera asistencia, consistía en otorgarles el bautismo y en emitir un certificado de remisión que facilitase su inmediato traslado e ingreso en la Casa Cuna de La Laguna. ${ }^{29}$ Un proceder similar al registrado en Almería, Santiago de Compostela o León, solo que, en esta última inclusa, el recurso a las cédulas certificadas se aplicaba a los ingresos temporales de hijos legítimos, haciendo constar en ellas la imposibilidad de los padres para asumir la crianza del recién nacido (FERNÁNDEZ OrTEGA, 1984: 151; Martínez Rodríguez, 2014: 279; Pérez Álvarez, 2008: 194). Por el contrario, y a diferencia de lo sucedido en Santiago, donde lo que se trataba era de facilitar el envío de la criatura a la Casa Cuna del Hospital Real, en Tenerife, estas cédulas eran empleadas además para dar cuenta de la mencionada pobreza de los padres, de aspectos protocolarios sobre el bautismo y, a veces, de manera opcional, de otros relativos a cómo había sido encontrada la criatura o a su entorno familiar.

Hecho esto, el sacerdote gestionaba el desplazamiento del expósito a la capital a manos de los conductores. No siempre conocemos quienes eran éstos, si bien, en ocasiones, sabemos que la conducción de los menores era llevada a cabo por las criadas de los propios curas, las parteras o las comadres de la parroquia. Este fue el caso de María de Candelaria, quien el 1 de octubre de 1792, después de haber caminado unos 35 kilómetros, entregaba en la Casa Cuna de La Laguna al expósito Gerónimo de la Concepción, al tiempo que afirmaba ser la criada del párroco del Realejo Bajo y advertía a las autoridades de la casa que la criatura había sido bautizada el día anterior en aquella parroquia con ese nombre. ${ }^{30}$

El abandono en una institución eclesiástica como esta, ya sea en la ciudad, los puertos, la villa o los enclaves rurales, evidencia la aceptación por parte de los

29 «Dominga de la O, expósita del lugar de Tacoronte, remitida por el venerado beneficiado de dicho lugar con papel de estar bautizada este día en aquella parroquia y con advertencia de ser hija de Teresa Cardozo de la propia vecindad de estado libre, pero tan pobre y desnuda, que se duda no pueda criarla y para no exponer esta inocente a morir la remite a la cuna y entró hoy en ella [ 25 de agosto de 1776]. Murió en 11 de noviembre de 1776». AHPT. Beneficencia, sig. VI-129. Libro de asiento, 17521794, f. 250.

$30 \mathrm{Y}$, aunque se olvidó de traer el papel que se le dio para la remisión, lo presentó luego, por lo que las autoridades de la institución entendieron que era cierto lo expresado por la dicha conductora. AHPT. Beneficencia, sig. VI-129. Libro de asiento, 1752-1794, s/f. 
progenitores de las normas sociales imperantes. Es decir, al obrar de este modo, evitaban cometer «pecados» peor considerados que la exposición, salvaban el alma de la criatura y eludían la práctica de un aborto o la comisión de un infanticidio. Sin embargo, lo cierto es que desconocemos la verdadera intención de los padres y madres cuando se decidían a exponer a sus hijos en un cruce de caminos, a la intemperie o en el pórtico de una Iglesia. Aun así, es evidente que optaron por el abandono y no por el infanticidio, elección que al menos otorgaba una mínima posibilidad de supervivencia a sus hijos. En estas condiciones, mantenerles consigo, podría haber puesto en peligro su situación personal y social, o la estabilidad de sus hogares y, por lo tanto, el recién nacido se vería afectado negativamente por lo que ocurriese con ellos. En suma, la exposición infantil parece haber sido la salida elegida por aquellas personas que estaban sometidas a un estrés general, ya sea a causa de la situación de pobreza material que se vivía en la isla en esos años o de cuestiones relativas a la honra familiar. Sea en uno u otro caso, su decisión tenía el respaldo de las autoridades eclesiásticas, tal y como lo indica el funcionamiento de los mecanismos de expedición y recepción de niños expósitos en la Casa Cuna de La Laguna.

\section{ANÁLISIS DE LOS INGRESOS EN LA CASA CUNA DE LA LAGUNA, SIGLOS XVIII-XIX}

Entre 1752 a 1794 ingresaron en la Casa Cuna de La Laguna un total de 5.466 recién nacidos, de los cuales un 48,9\% fueron niños, coincidiendo en esto con lo sucedido en otras inclusas europeas (HunECKE, 1991: 45; MARCOS, 1978: 134-135). En todo caso, este porcentaje disipa la posibilidad de que en Tenerife hubiese existido una tendencia a abandonar a las hijas frente a los hijos, por lo que es de suponer que la preeminencia de las niñas en las entradas registradas obedecería, como en la mayor parte de las casas europeas, a cuestiones biológicas. Con todo, hubo excepciones a este patrón de conducta, como por ejemplo sucedía en La Palma, Santiago de Compostela, Caen, Guimarães o Mallorca, donde los ingresos de niños fueron ligeramente superiores a los de las niñas (SANTANA Pérez, 2017: 152; Martínez RodrígueZ, 2014: 276-279; PAscual, 2016: 113-115). 


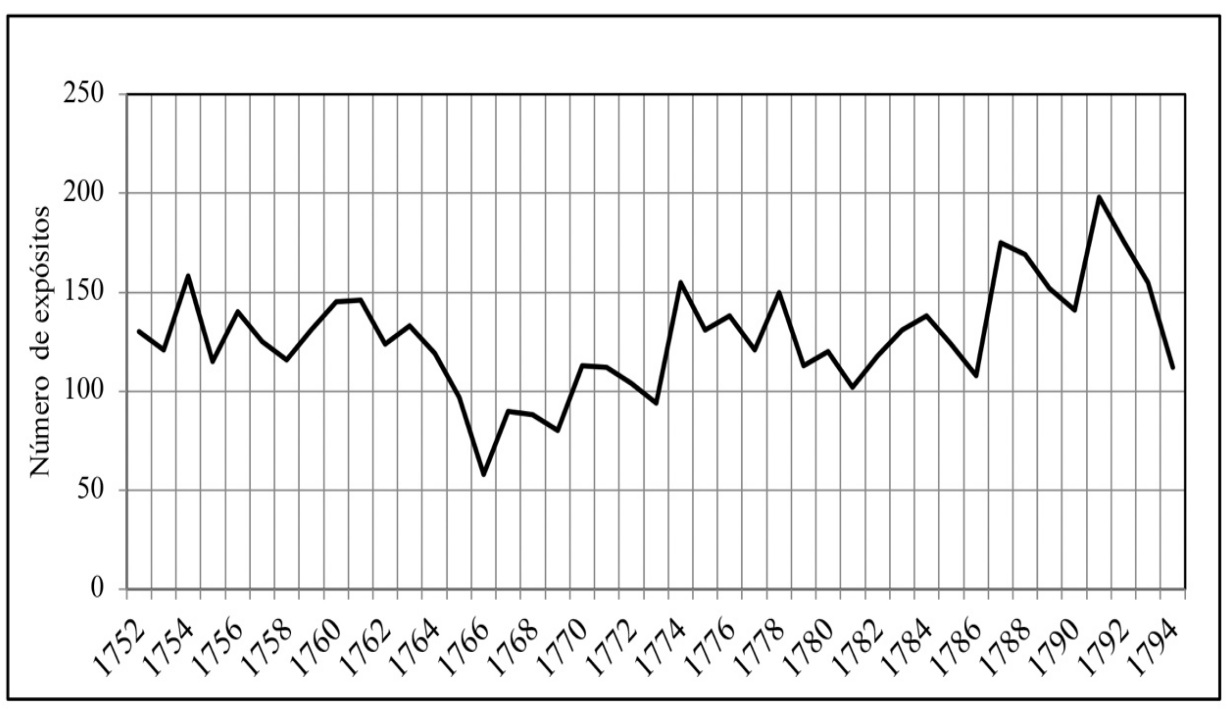

Fuente: AHPT. Beneficencia, sig. VI-129. Libro de asiento, 1752-1794. Elaboración propia.

La casa cuna recibió una media de 126 expósitos y expósitas al año entre 1752 y 1762. La situación cambia de forma repentina en octubre de 1763, cuando don Amaro José González de Mesa, reconocido como segundo administrador del centro, renuncia a su cargo. La vacante permaneció sin ser ocupada durante ocho meses, lo que provocó un rápido deterioro del funcionamiento del centro y de su capacidad de acogida, pues hasta 1765 se redujo a la mitad (Gráfico 1).

La casa tardó en recuperarse de este golpe, ocasionado por los problemas económicos que conoció entre 1763 y 1765, tal y como nos lo indican las sistemáticas solicitudes de ayuda que el nuevo administrador, don Andrés González Cabrera, envío por esos años a las autoridades laicas y eclesiásticas de la isla. En paralelo, y junto a los poderes locales y al sector ilustrado tinerfeño, solicitó a Carlos III la concesión de ciertas prebendas económicas relacionadas con el comercio realizado en los tres puertos principales de la isla, al objeto de sostener sin problemas el funcionamiento del establecimiento (SAntana Pérez, 1993: 72-76). Pese a lo infructuoso de estas gestiones, la perseverancia del administrador consiguió que los poderes locales se hiciesen responsables del pago de los salarios a las amas de cría y del costo de la manutención de los niños que habían sobrevivido y aún 
no podían cuidarse a sí mismos. ${ }^{31}$ Estas ayudas parece que se mantuvieron en el tiempo, pues, tal y como ha constatado Juan Manuel HernÁndez GonZÁLEz (1998: 63), el Ayuntamiento de La Laguna subvencionaba anualmente a la inclusa con 15.000 reales, cifra de la que existe constancia en los presupuestos del concejo municipal para los años que van de 1772 a 1851 (MARCos, 1996: 82-84).

En relación con este episodio, ya con un nuevo administrador y dinero, se explica entonces que entre 1766 y 1792 los ingresos de niños en la inclusa sigan una trayectoria alcista, interrumpida sólo de forma circunstancial en 1777-1780, a raíz, curiosamente, de otro cambio en la persona del mencionado administrador, puesto que en este caso pasó a ser ocupado por don Francisco de León y Ossorio hasta 1811 (Gráfico 1). De nuevo se pone de manifiesto que una vez que el administrador consigue hacerse con el control de la institución, a partir de 1780, la acogida de expósitos continúa con su ritmo alcista hasta 1792. Algo que se repite en años posteriores, pues don Diego Hernández López, comienza el 1 de agosto de 1844, ya como director interino hasta el 30 de junio de 1845, cuando la Junta de Beneficencia decidió nombrar al presbítero don Domingo Franchi. Estos últimos cambios vuelven a dejar su impronta en el ritmo de ingresos de los niños expósitos (Gráfico 2).

GRÁFICO 2

Evolución de las entradas de expósitos, 1811-1846

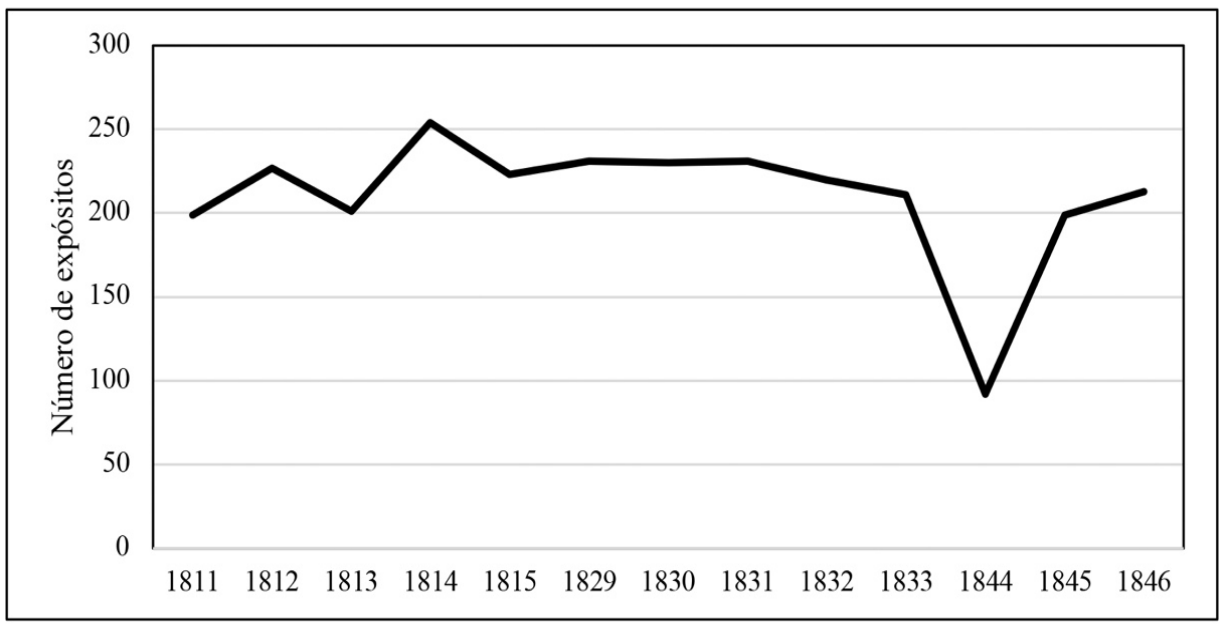

Fuentes: SANTANA PÉrez (1993: 94-101). AHPT. Beneficencia, sig. VI-133. Libro de asiento (1844-1846). Elaboración propia.

Resulta llamativo que sobre la capacidad de acogida de la casa hayan pesado 31 AHPT. Beneficencia, sig. 260. Reales cédulas de 1766-1767. 
tanto las mencionadas circunstancias económicas como la competencia de gestión que los administradores de la misma tenían. Es más, la particular sensibilidad de esa acogida a esa habilidad de gestión pone de manifiesto dos cosas. Primero, que al igual que sucedía en otros casos peninsulares, y en la media duración, la trayectoria de los abandonos en el torno de la ciudad estuvo influenciada por los factores que condicionaron el funcionamiento de las inclusas (DUBERT, 2013: 150151; FONTE, 2009: 71-84). Segundo, la enorme fragilidad institucional que caracterizó a la Casa Cuna de La Laguna, que parece haber sobrevivido y ser operativa solo gracias al empeño personal y a la dedicación de sus administradores, visto que cuando el uno y la otra flaqueaban, el servicio que ésta prestaba a la comunidad se resentía. Sin olvidar, los importantes efectos provocados en la sociedad a raíz de los cambios económicos y demográficos que tuvieron lugar en Canarias durante el tránsito del siglo XVIII al XIX (MACíAS, 1995: 174-181; CABRERA y DíAZ, 2011a: 17-33; DíAz HernándeZ, 2011: 35-43; CODERCH, 1975; Quirós, 1971).

Los ingresos de expósitos en la inclusa de La Laguna registrados durante la segunda mitad del siglo XVIII estuvieron, además, condicionados por el calendario agrario, ya que, y como se ha mencionado, aunque el grueso de los abandonos tenía lugar en el área urbana la procedencia de la mayoría de los niños era de origen rural. Conforme a ello, durante los meses de invierno, en especial entre enero y febrero, esos abandonos se acentuaban, debido sobre todo al endurecimiento que suponían las condiciones materiales de vida en el curso de la estación. El descenso de las actividades productivas en el campo mermaba los ingresos económicos y las despensas de los hogares campesinos, sometiendo a éstos a períodos de estrés alimenticio, circunstancia que perjudicaba la salud de las mujeres embarazadas e interrumpía los períodos de lactancia de sus hijos. ${ }^{32}$ Así, y ante la imposibilidad de alimentar al pequeño en el hogar, la familia se veía obligada entonces a entregar o a dejar temporalmente a su criatura en la Casa Cuna de La Laguna. ${ }^{33}$ De la misma manera, lo hacían muchas de las jóvenes solteras que, en distintas circunstancias y por las razones apuntadas, los habían concebido durante la primavera pasada. De hecho, los expósitos ingresados a lo largo del invierno habían sido concebidos entre finales de la primavera y los inicios del verano (Gráfico 3). En esa época del año, la comunidad en su conjunto participaba de las tareas agrícolas, las cuales favorecían la interacción y la estrecha convivencia de personas de distinto sexo, lo que como resultado solía desembocar, en ocasiones, en embarazos no deseados para las jóvenes solteras, al igual como sucedía también en otras comunidades rurales peninsulares.

Pero la vida de estas poblaciones se hallaba a su vez condicionada por el

32 «Rafael José de la Concepción, expósito de La Laguna, hijo natural de Josefa Ana Rodríguez, vecina del pago del Rosario, donde la llaman la gotera. Lo trajo a la cuna el día 4 de febrero de 1775 su abuela, Josefa Rodríguez, por la pobreza y la falta de leche de su madre en aquel día. Murió el 23 de abril de 1776». AHPT. Beneficencia, sig. VI-129. Libro de asiento, 1752-1794, f. 213.

33 «Josefa Joaquina de los Dolores, hija legítima de Francisco Luis y de Josefa Antonia de los Remedios vecinos de esta ciudad, que nació el día 19 de [marzo de 1776] y se bautizó el 24 del mismo en la parroquia de Nuestra Señora de los Remedios. Se admitió este día [30 de marzo de 1776] en la cuna por habérsele secado la leche a su madre y no tener arbitrio con que pagar ama de cría. Se entregó a sus padres en 30 de junio de 1776». AHPT. Beneficencia, sig. VI-129. Libro de asiento, 1752-1794, f. 240. 
calendario litúrgico. De ello tenemos una clara muestra en las entradas de la casa cuna, pues las caídas de ingresos registradas entre febrero y marzo se debían a la Cuaresma, período religioso que sigue al Carnaval. Luego de estas fechas, el calendario agrícola volvía a imponerse, ya que los trabajos de la tierra en primavera y verano hacían que la exposición no fuese tan intensa, en parte, también, porque las familias contaban con qué alimentar a sus pequeños. Sin embargo, a medida que avanzaba el otoño y se abría el invierno el abandono volvía a dispararse, en sintonía con las crecientes dificultades que experimentaban muchas despensas campesinas (Gráfico 3). En suma, una estacionalidad muy semejante a la registrada a este nivel en la isla de Gran Canaria y en otros puntos de la península y Europa (Lobo, 1993: 47-53; Sobrado, 2001: 462; Martínez RodríGueZ, 2014: 296; TorRubia, 2004: 106-109).

GRÁFICO 3

Estacionalidad de las exposiciones, 1752-1794

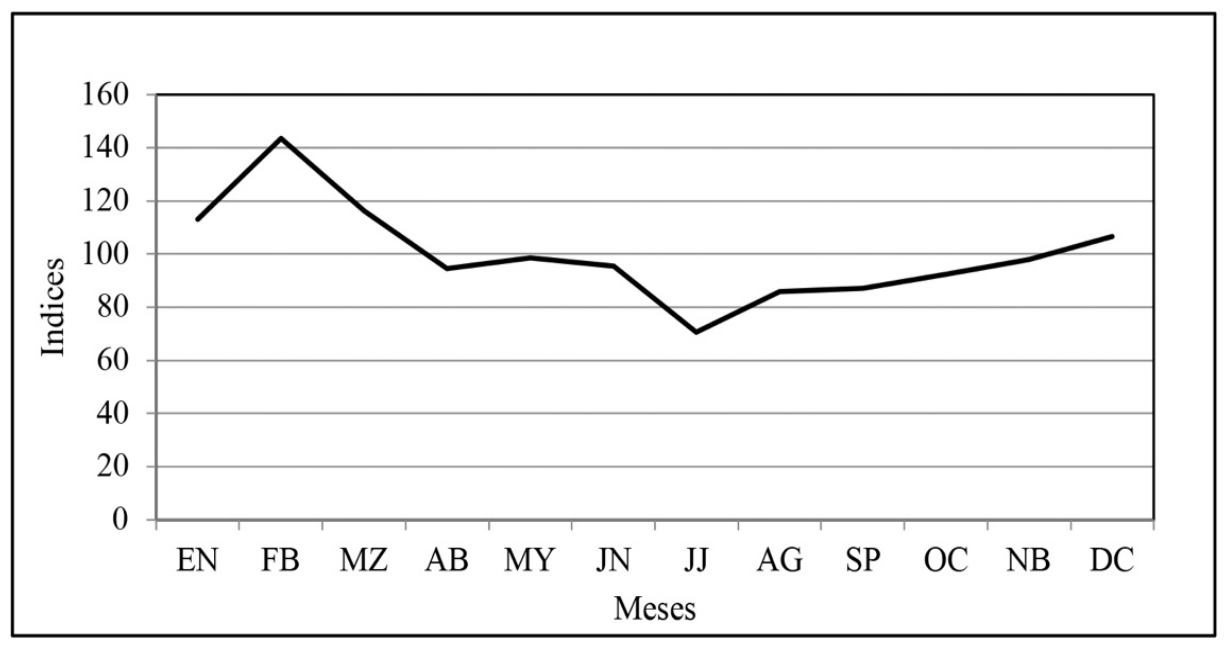

Fuente: AHPT. Beneficencia, sig. VI-129. Libro de asiento, 1752-1794. Elaboración propia.

Los ingresos de expósitos ocurridos en 1875-1889 en la Casa de la Maternidad y Expósitos de Santa Cruz de Tenerife, muestran una situación diferente a la existente en La Laguna entre 1752 y 1794, ya que el descenso operado en el número medio anual de entradas de uno a otro momento es de entorno a un $40 \%$. Es más, a finales del siglo XIX esas entradas caen sin detenerse desde 1875 y, en conjunto, lo hacen hasta un 43\% en 1875-1889 (Gráfico 4). A finales del siglo XIX la exposición se hace eco así de los cambios que la administración del Estado liberal introdujo para combatir el fenómeno. Este es el caso de la supresión del torno, de la obligación de registrar el nombre de la madre o de la persona que entregaba 
el pequeño o de los nuevos cuidados otorgados a las criaturas, gracias en buena medida al desarrollo que estaba conociendo la Pediatría. Al mismo tiempo, y ya en un plano social, es ahora cuando se siente sobre la infancia en general, y sobre la abandonada en particular, la nueva mirada que sobre ella alentaban las capas altas de la sociedad (DuBERT, 2013: 141; LAMSFus, 1991: 1187).

GRÁFICO 4

Evolución de las entradas de expósitos, 1875-1889

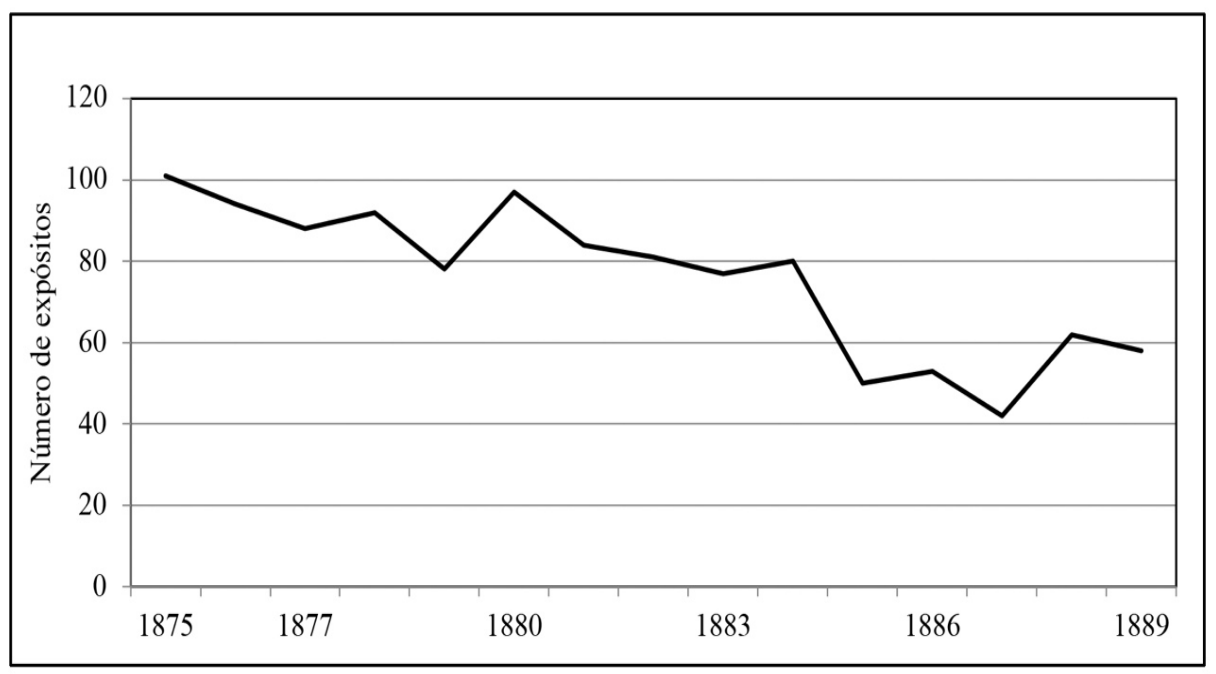

Fuente: AHPT. Beneficencia, sig. IV-287. Libro de asiento, 1874-1889. Elaboración propia.

En este sentido, no hay que olvidar, los importantes cambios que se dieron en la economía insular. De tal modo, que la crisis comercial que en 1852 produjo en las islas la entrada en vigor del decreto de los Puertos Francos, sólo comenzó a ser superada a partir de mediados de la década de 1870, gracias, en buena medida, a inversiones de capital extranjero, que revitalizaron la vida económica y social de las islas Canarias, contribuyendo así también a explicar el descenso de la exposición infantil (MaCías y RodríGuez MarTín, 1995: 371-406; CASTELlano y Macías, 1997: 79; Cabrera y SuÁrez, 2011: 45-58; Cabrera y Díaz, 2011b: 198211). En suma, y de manera semejante a como sucedía a finales del siglo xVIII la nueva situación se dejó sentir sobre la serie de circunstancias que rodeaban y estimulaban el abandono de niños en la inclusa de Santa Cruz. 


\section{CONCLUSIONES}

Al igual a como sucedía en las sociedades europeas y españolas durante el Antiguo Régimen, en general en Canarias, y en particular en Tenerife, el fenómeno de la exposición infantil se intensificó entre finales del siglo XVIII y principios del siglo xIx. En la isla, el abandono fue un recurso empleado por las madres y familias ante la precariedad material en que vivían, la cual en ocasiones hacía que les fuera imposible mantener consigo a sus recién nacidos. En estas circunstancias, podían dejar a sus pequeños expuestos durante la noche en el torno de la ciudad. Por este proceder, al menos, le otorgaban a sus criaturas una mínima posibilidad de vivir mientras que burlaban la presión social y parroquial que pesaba sobre su comportamiento.

La concurrencia en el torno fue mayor durante los meses de invierno, cuando las despensas de las familias campesinas se resentían por el descenso que por estos períodos se producía en las actividades agrícolas. Las personas que decidieran no viajar hasta La Laguna o quienes carecían de la posibilidad de hacerlo, contaban con los mecanismos de traslado y recepción de niños expósitos que se apoyaban en las parroquias, donde los curas se encargaban de enviar a las criaturas expuestas hasta la ciudad. Además, en Santa Cruz y en La Laguna, existía asimismo un grupo de mujeres que trasladaba a los pequeños desde los brazos de sus madres hasta la inclusa. En el interior del establecimiento aquellos que carecían de una cédula certificada de bautismo, eran cristianados nada más llegar. Luego, y si sobrevivían, debían esperar a la llegada de su ama de leche, quien vivía en las zonas próximas a la ciudad, donde finalmente el expósito sería criado y alimentado junto a los hijos de su nodriza hasta que cumpliera los tres años, momento que dejaba su hogar para ser prohijado o incorporarse al mundo de la marginalidad social.

A pesar de las serias dificultades que condicionaron el funcionamiento de la Casa Cuna de La Laguna, su personal procuró mantener los servicios que la inclusa prestaba a la comunidad. En la segunda mitad del siglo xIx la mencionada casa se traslada a Santa Cruz y su influencia supera los límites de la isla de Tenerife. Desde entonces, a ella eran enviados los niños expósitos abandonados en las islas de La Palma, La Gomera y El Hierro. Una situación que exigía seguir contando con los tradicionales puntos de recepción y traslado, pero ya no se apoyarían en las feligresías insulares, visto que esta función fue transferida a los hospitales y a los alcaldes municipales. Pese a ello, la práctica del abandono infantil fue perdiendo fuerza en el curso de la segunda mitad del siglo XIx. En buena medida, gracias a los cambios que se dieron en la coyuntura económica isleña y a las modificaciones que se introdujeron en el funcionamiento de las inclusas a partir de 1850-1860. 


\section{FUENTES}

Archivo Histórico Provincial de Santa Cruz de Tenerife (AHPT). Agrupación de fondos de Beneficencia. Signatura 260. Reales cédulas motivadas por la petición de ayuda hecha por don Andrés González Cabrera, capellán del Hospital de los Dolores, para la Cuna de Expósitos, cuya situación describe de la mayor miseria (1766-1767).

Archivo Histórico Provincial de Santa Cruz de Tenerife (AHPT). Agrupación de fondos de Beneficencia. Signatura 934. Memoria descriptiva de los Establecimientos Provinciales de Beneficencia que existen en la Provincia de Canarias en 1887.

Archivo Histórico Provincial de Santa Cruz de Tenerife (AHPT). Agrupación de fondos de Beneficencia. Signatura VI-129. Libro en que se anotan los niños que se exponen [y reciben] en la Cuna y Casa de expósitos de esta ciudad de La Laguna (17521794).

Archivo Histórico Provincial de Santa Cruz de Tenerife (AHPT). Agrupación de fondos de Beneficencia. Signatura VI-133. Libro de filiaciones y defunciones de los niños expósitos que han entrado en la cuna de esta ciudad de La Laguna desde el 1 de agosto de 1844 hasta fin de diciembre de 1846.

Archivo Histórico Provincial de Santa Cruz de Tenerife (AHPT). Agrupación de fondos de Beneficencia. Signatura IV-287. Casa de maternidad y expósitos. Índice de acogidos (1874-1889).

Instituto Nacional de Estadística. Censo de 1787. Floridablanca. Madrid, 1987.

\section{REFERENCIAS}

Álvarez Santaló, L. (1977): «La Casa de Expósitos de Sevilla en el siglo xVII», Cuadernos de Historia del Instituto Jerónimo Zurita, 7: 491-532.

Álvarez SANTALó, L. (1980): Marginación social y mentalidad en Andalucía occidental: expósitos en Sevilla, 1613-1910, Sevilla, Junta de Andalucía.

BARDET, J. (1991): «La société et l'abandon», en Enfance abandonnée et société en Europe, xIve-Xxe siècles, Actes du Colloque International, École Française de Rome, Roma: 3-26.

Cabrera Armas, L.; DíAz de la PAZ, Á. (2011a): «La quiebra de las bases económicas tradicionales», en A. Millares, S. Millares, F. Quintana y M. SuÁrez (dirs.), Historia contemporánea de Canarias, Ágora, Las Palmas de Gran Canaria: 17-33.

Cabrera Armas, L.; Díaz de la PAz, Á. (2011b): «El apogeo del nuevo modelo de crecimiento económico», en A. Millares, S. Millares, F. Quintana y M. SuÁrez (dirs.), Historia contemporánea de Canarias, Ágora, Las Palmas de Gran Canaria: 97-235.

Cabrera Armas, L.; SuÁrez Bosa, M. (2011): «La implantación de un nuevo modelo económico», en A. Millares; S. Millares; F. Quintana y M. Suárez (dirs.), Historia contemporánea de Canarias, Ágora, Las Palmas de Gran Canaria: 45-58.

Castellano Gil, J.; Macías Martín, F. (1997): Historia de Canarias, Centro de la Cultura Popular Canaria, Tenerife. 
Cioranescu, A. (1965): La Laguna. Guía histórica y monumental, Litografía A. Romero, Santa Cruz de Tenerife.

Coderch FigueroA, M. (1975): La evolución de la población de La Laguna entre 17501860, Instituto de Estudios Canarios, La Laguna.

Corsini, C. (1996): «Enfance et famille au Xixe siècle» en E. BECchi y D. Julia (dir.), Histoire de l'enface en Occident, vol. 2, Seuil, Paris: 289-327.

DEMERSON, P. (1972): «La Real Inclusa de Madrid a finales del siglo XVIII», Anales del Instituto de Estudios Madrileños, 8: 261-272.

DíAz HERNÁNDEZ, R. (2011): «La pervivencia del régimen demográfico antiguo», en A. Millares; S. Millares, F. Quintana y M. SuÁRez (dirs.), Historia contemporánea de Canarias, Ágora, Las Palmas de Gran Canaria: 35-43.

Dos Guimarães SÁ, I. (1992): The Circulation of Children in Eighteenth Century Southern Europe: the Case of the Foundling Hospital of Porto, Tesis doctoral, Instituto Universitario Europeo, Firenze.

DuBERT, I. (1988): «Mecanismos asistenciales y mortalidad infantil en la Galicia cantábrica. El Hospital de San Pablo de Mondoñedo de 1780 a 1850», en R. Villares PAz (coord.), La ciudad y el mundo urbano en la historia de Galicia, Tórculo Edicións, Santiago de Compostela: 199-223.

Dubert, I. (2013): «L'abandon d'enfants dans l'Espagne de l'Ancien Regime: réevaluer l'ampleur et les causes du phénomène», Annales de Démographie Historique, 1: 165-210.

Dubert, I. (2017): «Población flotante y asistencia hospitalaria. Santiago de Compostela, siglos XIX-XX», en I. DubERT y V. GOURDON (ed.), Inmigración, trabajo y servicio doméstico en la Europa urbana, siglos XVIII-XX, Casa de Velázquez, Madrid: 135-154.

EGIDO LóPEZ, T. (1973): «La cofradía de San José y los niños expósitos de Valladolid (1540-1757)», Estudios Josefinos, 27: 77-100.

EGIDO LÓPEZ, T. (1975): «Aportación al estudio de la demografía Española: los niños expósitos de Valladolid (siglos XVI-XVIII)», en I Jornada de Metodología Aplicada a las Ciencias Históricas, Historia Moderna, Universidad de Santiago de Compostela, Santiago de Compostela: 333-345.

EGIDO LópeZ, T. (2003): «La marginación moral. Balance de la investigación histórica de los niños expósitos, 1973-2001», en R. López y D. Lopo (ed.), Balance de la Historiografía Modernista, 1973-2001, Actas del VI Coloquio de Metodología Histórica Aplicada, Xunta de Galicia. Santiago de Compostela: 393-404.

Eiras Roel, A. (1967-68): «La Casa de Expósitos del Real Hospital de Santiago en el siglo XVIII», Boletín de la Universidad Compostelana, Santiago de Compostela: 295-355.

FERNÁNDEZ ORTEGA, A. (1984-85): «La ordenanza para la administración del ramo de niños expósitos de la diócesis de Almería del año 1763», Chronica Nova, 14: 147-159.

FERnÁNDez Ugarte, M. (1988): Expósitos en Salamanca a comienzos del siglo XVIII, Diputación de Salamanca, Salamanca.

FONTE DA, T. (2009): «A assitência à infância abandonada no noroeste peninsular. Instituições, quadros normativos, estratégias familiares e circulação de 
crianças entre o Minho e a Galiza nos séculos XVIII a XX», en I. DubERT y H. SoBrADo (eds.), O mar nos séculos modernos, tomo I, Xunta de Galicia, Santiago de Compostela: 71-84.

Fuente Galán, M. (2000): Marginación y pobreza en la Granada del siglo XVIII: los niños expósitos, Universidad de Granada, Granada.

Galicia Pinto, M. (1985): La Real Casa Hospicio de Zamora: asistencia social a marginados (1798-1850), CSIC, Diputación Provincial de Zamora, Zamora.

Gonzalbo Aizpuru, P. (1982): «La casa de niños expósitos de la ciudad de México. Una fundación del siglo XVIII», El Colegio de México, 31 (3): 409-430.

GONZÁlez YANES, E. (1955): «Las primeras entidades de asistencia pública de Tenerife», Revista de Historia, 109-112: 30-88.

Gutiérrez Lorenzo, M.; García CORZO, R. (2010): «Discursos y prácticas asistenciales acerca del abandono y la exposición infantil en la Nueva Galicia entre la colonia y la independencia», en M. Lobo dE ARAúJo; F. Moura y A. Esteves (orgs.), Pobreza e assistência no espaço Ibérico (Séculos XVI-XX), CITCEM, Portugal: 69-81.

Hernández GonzÁlez, M. (1998): Mujer y vida cotidiana en Canarias en el siglo XVIII, Centro de la Cultura Popular Canaria, Tenerife.

HunECKe, V. (1991): «Intensitá e fluttuazioni degli abbandoni dal XV al XIX secolo», en Enfance abandonee et société en Europe, xive-xxe siècles, Actes du Colloque International, École Française de Rome, Roma: 27-72.

LeÓn Govantes, M. (2015): «Aproximación a la documentación de la Casa Cuna de expósitos de La Palma: libros-registros de ingresos (1877-1969)», Revista canaria de patrimonio documental, 11: 255-271.

LeVENE, A. (2006): «The survival prospect of European foundlings in the XVIIIthcentury: The London Foundling Hospital and the Hospedale degli Innocenti of Florence», Popolazione e Storia, 2: 61-84.

Lobo Cabrera, M.; Sediles García, M. (1988): «Expósitos e ilegítimos en Las Palmas en el siglo XVII», Anuario de Estudios Atlánticos, 34: 159-203.

Lobo Cabrera, M.; López Caneda, R.; Torres Santana, E. (1993): La «otra» población: expósitos, ilegítimos y esclavos. (Las Palmas de Gran Canaria Siglo XVIII), Universidad de Las Palmas de Gran Canaria, Las Palmas de Gran Canaria.

Lobo Cabrera, M.; Rodríguez Segura, A. (2002): «La ilegitimidad en el medio rural. El caso de la Vega en Gran Canaria», en F. Morales (coord.), Actas del XV Coloquio de Historia Canario-Americana, Cabildo de Gran Canaria, Las Palmas de Gran Canaria: 411-431.

Lobo CABrera, M. (2009): «Grupos sociales marginados: esclavos, expósitos y gitanos», en J. BRAVO y L. SANZ (coord.), Población y grupos sociales en el Antiguo Régimen, IX Reunión Científica de la Fundación Española de Historia Moderna, Universidad de Málaga, Málaga: 131-146.

López Picher, M. (2006): «Los primeros años de la inclusa de La Coruña, bajo el patronato de la venerable Congregación del Divino Espíritu Santo y María Santísima de los Dolores (1793-1799)», en F. CAMpos (coord.), La Iglesia española y las instituciones de caridad, La Coruña: 597-616.

Macías HernándeZ, A. (1995): «Economía Moderna, siglos XV-XVIII», en A. 
Bethencourt (ed.), Historia de Canarias, Ediciones del Cabildo Insular de Gran

Canaria, Las Palmas de Gran Canaria: 133-191.

Macías Hernández, A.; Rodríguez Martín, J. (1995): «Economía Contemporánea», en A. Bethencourt (ed.), Historia de Canarias, Ediciones del Cabildo Insular de Gran Canaria, Las Palmas de Gran Canaria: 369-430.

Marcos Martín, A. (1978): Auge y declive de un núcleo mercantil y financiero de la Castilla La Vieja. Evolución demográfica de Medina del Campo durante los siglos XVI y XVII, Secretariado de publicaciones, Universidad de Valladolid, Valladolid.

Marcos Martín, A. (1996): «Exposición y muerte. La mortalidad de expósitos en

España en el tránsito del siglo XVIII al XIX», en D. REHER (coord.), Actas do III Congresso da ADEH, Ediçôes Afrontamento, Porto: 59-86.

Martín Ruíz, J.F.; DíAz Rodríguez, M.C. (1982): «La natalidad ilegítima en la formación social canaria. Las repercusiones de la emigración americana», en F. Morales (coord.), Actas del V Coloquio de Historia Canario-Americana, Vol. 1, Ediciones del Cabildo Insular de Gran Canaria, Las Palmas de Gran Canaria: 203-218.

Martínez Rodríguez, E. (2014): La población de Santiago de Compostela (1630-1860). Estructuras, coyunturas y comportamientos demográficos, Universidad de Santiago de Compostela, Santiago de Compostela.

Moyano BAZZANI, E. (2000): «Notas sobre la beneficencia en Canarias a mediados del siglo XIX», en F. Morales (coord.), Actas del XIII Coloquio de Historia CanarioAmericana, VIII Congreso Internacional de Historia de América, Cabildo Insular de Gran Canaria, Las Palmas de Gran Canaria: 2363-2397.

PAscual RAmos, E. (2016): «Hospicios y expósitos en Mallorca durante el siglo XVIII (1701-1812)», Saitabi, 66: 101-119.

Pérez Álvarez, M. J.; Martín García, A. (2008): Marginación, infancia y asistencia en la provincia de León a finales del Antiguo Régimen, Universidad de León, León.

Pérez GarcíA, J. (1976): «La mortalidad infantil en Galicia en el siglo XIx. El ejemplo de los expósitos del Hospital Real de los Reyes Católicos de Santiago de Compostela», Liceo Franciscano, 85-87: 171-197.

Pérez Morera, J. (2019): «Arquitectura asistencial e iconografía hospitalaria. Uso y función de una Casa-Hospital del siglo XVI», Revista de Historia Canaria, 201:185-242.

Quintana Andrés, P.; Lobo Cabrera, M. (1996): «Expósitos en la isla de La Palma (1673-1757)», Anuario de Estudios Atlánticos, 44: 809-884.

Quirós LinAREs, F. (1971): La población de La Laguna (1837-1960), Instituto de Estudios Canarios, La Laguna.

Rey Castelao, O.; Rial García, S. (2009): Historia de las mujeres en Galicia, siglos XVI al XIX, Nigratrea, Vigo.

RodRíGUEZ YANES, J. (1997): «Grupos humanos desfavorecidos. Pobres, marginados y asistencia social» en J. RoDRíGUEZ YANES, La Laguna durante el Antiguo Régimen. Desde su fundación hasta finales del siglo XVII, Volumen II, Ayuntamiento de San Cristóbal de La Laguna, Tenerife: 810-854.

SANTANa PÉrez, J. (1993): Cunas de expósitos y hospicios en Canarias (1700-1837),

Cabildo Insular de Gran Canaria, Madrid. 
Santana Pérez, J.; Monzón Perdomo, M. (1995): Hospitales de La Laguna durante el siglo XVIII, Ayuntamiento de San Cristóbal de La Laguna, Tenerife.

SANTANA PÉrez, J. (2017): «Expósitos e ilegítimos: concebidos en pecado, hijos de un dios bastardo, hijos de la vergüenza», en M. DE PAz, Canarias insólita. Bestias, fenómenos y calamidades, Herques, Santa Cruz de Tenerife: 143-153.

SARASÚA, C. (1994): Criados, nodrizas y amos. El servicio doméstico en la formación del mercado de trabajo madrileño, 1758-1868, Siglo Veintiuno de España Editores, Madrid.

Sobrado Correa, H. (2001): Las tierras de Lugo en la Edad Moderna. Economía campesina, familia y herencia, 1550-1860, Fundación Pedro Barrié de la Maza, A Coruña.

Sobrado Correa, H.; Dubert, I. (2012): «La familia y las edades de la vida», en I. Dubert (coord.), Historia de la Galicia Moderna, Universidade de Santiago de Compostela, Santiago de Compostela: 95-150.

Sobrado Correa, H. (2018): «Desamparo y marginación infantil en Galicia en los siglos XVIII y XIX», en M. Lobo de Araújo y A. Martin García (cords.), Os Marginais, séculos XVI-XIX, Edições Húmus, Portugal: 35-57.

SOUBEYROUX, J. (1980): «Pauperismo y relaciones sociales en el Madrid del siglo XVIII», Estudios de Historia Social, 12-13: 7-227.

Torres Santana, E.; Lobo Cabrera, M. (1996): "Los otros a partir de la obra de Domínguez Ortiz», Revista d'història moderna, 14: 99-118.

Torrubia Balagué, E. (2004): Marginación y pobreza. Expósitos en Salamanca (17941825), Diputación de Salamanca, Salamanca.

VALVerde LAMSFus, L. (1990): «Los niños expósitos y sus nodrizas en el País Vasco (siglos XVIII y XIX)», Vasconia, 17: 230-262.

VAlverde LAMSFUS, L. (1991): «Legitimidad e ilegitimidad. Evolución de las modalidades de ingreso en la Inclusa de Pamplona, 1740-1934», en Enfance abandonnée et société en Europe, XIve-Xxe siècle, Actes du colloque international de Rome (30 et 31 janvier 1987), École Française de Rome, Roma: 1169-1197. 
